\title{
Coupled fixed and coincidence points for monotone operators in partial metric spaces
}

\author{
Saud M Alsulami, Nawab Hussain and Abdullah Alotaibi*
}

${ }^{\text {"Correspondence: }}$

aalotaibi@kau.edu.sa

Department of Mathematics, King

Abdulaziz University, P.O. Box:

80203, Jeddah, 21589, Saudi Arabia

\begin{abstract}
In this paper, we prove some coupled fixed point results for $(\phi, \varphi)$-weakly contractive mappings in ordered partial metric spaces. As an application, we establish coupled coincidence results without any type of commutativity of the concerned maps. Consequently, the results of Luong and Thuan (Nonlinear Anal. 74:983-992, 2011), Alotaibi and Alsulami (Fixed Point Theory Appl. 2011:44, 2011) and many others are extended to the class of ordered partial metric spaces.
\end{abstract}

Keywords: coupled fixed point; partial metric space; comparison functions; coupled coincidence point

\section{Introduction}

The Banach contraction principle is the most celebrated fixed point theorem. Afterward many authors obtained various important extensions of this principle (see [1]). The concept of partial metric spaces was introduced by Matthews [2] in 1994. A partial metric space is a generalized metric space in which each object does not necessarily have to have a zero distance from itself. A motivation behind introducing the concept of a partial metric was to obtain appropriate mathematical models in the theory of computation and, in particular, to give a modified version of the Banach contraction principle [3, 4]. Subsequently, several authors studied the problem of existence and uniqueness of a fixed point for mappings satisfying different contractive conditions on partial metric spaces (e.g., [5-7]).

Recently, Bhaskar and Lakshmikantham [8] presented coupled fixed point theorems for contractions in partially ordered metric spaces. Luong and Thuan [9] presented nice generalizations of these results. Alotaibi and Alsulami [10] further extended the work of Luong and Thuan to coupled coincidences. For more related work on coupled coincidences we refer the readers to recent work in [11-16]. Our main aim in this paper is to extend Luong and Thuan [9] results to ordered partial metric spaces. We shall also establish coupled coincidence results and show that main results in [10] hold in ordered partial metric spaces without the compatibility of maps.

\section{Basic concepts}

We start by recalling some definitions and properties of partial metric spaces.

Definition 2.1 A partial metric on a nonempty set $X$ is a function $p: X \times X \rightarrow \mathbb{R}^{+}$such that for all $x, y, z \in X$,

() 2012 Alsulami et al: ilicensee Springer. This is an Open Access article distributed under the terms of the Creative Commons Attribution License (http://creativecommons.org/licenses/by/2.0), which permits unrestricted use, distribution, and reproduction in any medium, provided the original work is properly cited. 
p1. $x=y \Leftrightarrow p(x, x)=p(x, y)=p(y, y)$.

p2. $p(x, x) \leq p(x, y)$.

p3. $p(x, y)=p(y, x)$.

p4. $p(x, z) \leq p(x, y)+p(y, z)-p(y, y)$.

A partial metric space is a pair $(X, p)$ such that $X$ is a nonempty set and $p$ is a partial metric on $X$.

From the above definition, if $p(x, y)=0$, then $x=y$. But if $x=y, p(x, y)$ may not be 0 in general. A trivial example of a partial metric space is the pair $\left(\mathbb{R}^{+}, p\right)$, where $p: \mathbb{R}^{+} \times \mathbb{R}^{+} \rightarrow$ $\mathbb{R}^{+}$is defined as $p(x, y)=\max \{x, y\}$. For some more examples of partial metric spaces, we refer to $[4,6]$.

Each partial metric $p$ on $X$ generates a $T_{0}$ topology $\tau_{p}$ on $X$ which has as a base the family of open $p$-balls $\left\{B_{p}(x, \epsilon): x \in X, \epsilon>0\right\}$, where $B_{p}(x, \epsilon)=\{y \in X: p(x, y)<p(x, x)+\epsilon\}$ for all $x \in X$ and $\epsilon>0$. A sequence $\left\{x_{n}\right\}$ in $X$ converges to a point $x \in X$, with respect to $\tau_{p}$ if and only if $p(x, x)=\lim _{n \rightarrow \infty} p\left(x, x_{n}\right)$. A sequence $\left\{x_{n}\right\}$ in $X$ is called a Cauchy sequence if $\lim _{n, m \rightarrow \infty} p\left(x_{n}, x_{m}\right)$ exists and is finite.

If $p$ is a partial metric on $X$, then the function $p^{s}: X \times X \rightarrow \mathbb{R}^{+}$given by

$$
p^{s}(x, y)=2 p(x, y)-p(x, x)-p(y, y)
$$

is a metric on $X$.

Lemma 2.1 $[2,7]$ Let $(X, p)$ be a partial metric space. Then

(a) $\left\{x_{n}\right\}$ is a Cauchy sequence in $(X, p)$ if and only if it is a Cauchy sequence in the metric space $\left(X, p^{s}\right)$.

(b) $(X, p)$ is complete if and only if the metric space $\left(X, p^{s}\right)$ is complete. Furthermore, $\lim _{n \rightarrow \infty} p^{s}\left(x_{n}, x\right)=0$ if and only if

$$
p(x, x)=\lim _{n \rightarrow \infty} p\left(x_{n}, x\right)=\lim _{n, m \rightarrow \infty} p\left(x_{n}, x_{m}\right) .
$$

Let $(X, p)$ be a partial metric. We endow the product space $X \times X$ with the partial metric $q$ defined as follows:

$$
\text { for }(x, y),(u, v) \in X \times X, \quad q((x, y),(u, v))=p(x, u)+p(y, v) .
$$

A mapping $F: X \times X \rightarrow X$ is said to be continuous at $(x, y) \in X \times X$ if for each $\epsilon>0$, there exists $\delta>0$ such that $F\left(B_{q}((x, y), \delta)\right) \subseteq B_{p}(F(x, y), \epsilon)$.

Definition 2.2 (Mixed monotone property) Let $(X, \preceq)$ be a partially ordered set and $F: X \times X \rightarrow X$. We say that the mapping $F$ has the mixed monotone property if $F$ is monotone non-decreasing in its first argument and is monotone non-increasing in its second argument. That is, for any $x, y \in X$,

$$
x_{1}, x_{2} \in X, \quad x_{1} \preceq x_{2} \quad \Rightarrow \quad F\left(x_{1}, y\right) \preceq F\left(x_{2}, y\right)
$$

and

$$
y_{1}, y_{2} \in X, \quad y_{1} \preceq y_{2} \quad \Rightarrow \quad F\left(x, y_{1}\right) \succeq F\left(x, y_{2}\right) .
$$


Definition 2.3 [11] Let $F: X \times X \rightarrow X$. We say that $(x, y) \in X \times X$ is a coupled fixed point of $F$ if $F(x, y)=x$ and $F(y, x)=y$.

Definition 2.4 (Mixed $g$-monotone property [11]) Let $(X, \preceq)$ be a partially ordered set and $F: X \times X \rightarrow X$. We say that the mapping $F$ has the mixed $g$-monotone property if $F$ is monotone $g$-non-decreasing in its first argument and is monotone $g$-non-increasing in its second argument. That is, for any $x, y \in X$,

$$
x_{1}, x_{2} \in X, \quad g x_{1} \preceq g x_{2} \quad \Rightarrow \quad F\left(x_{1}, y\right) \preceq F\left(x_{2}, y\right)
$$

and

$$
y_{1}, y_{2} \in X, \quad g y_{1} \preceq g y_{2} \quad \Rightarrow \quad F\left(x, y_{1}\right) \succeq F\left(x, y_{2}\right) .
$$

Definition 2.5 [11] Let $F: X \times X \rightarrow X$ and $g: X \rightarrow X$. We say that $(x, y) \in X \times X$ is a coupled coincidence point of $F$ and $g$ if $F(x, y)=g x$ and $F(y, x)=g y$.

\section{Coupled fixed point results}

Let $\Phi$ denote all functions $\phi:[0, \infty) \rightarrow[0, \infty)$ which satisfy

$(\phi 1) \phi$ is continuous and non-decreasing,

$(\phi 2) \phi(t)=0$ if and only if $t=0$,

$(\phi 3) \phi(t+s) \leq \phi(t)+\phi(s), \forall t, s \in[0, \infty)$,

$(\phi 4) \phi(\alpha x) \leq \alpha \phi(x)$ for $\alpha \in(0, \infty)$,

and let $\Psi$ denote all functions $\psi:[0, \infty) \rightarrow(0, \infty)$ which satisfy $\lim _{t \rightarrow r} \psi(t)>0$ for all $r>0$ and $\lim _{t \rightarrow 0^{+}} \psi(t)=0$.

Now, we state and prove our main result.

Theorem 3.1 Let $(X, \preceq)$ be a partially ordered set and suppose there is a partial metric $p$ on $X$ such that $(X, d)$ is a complete partial metric space. Let $F: X \times X \rightarrow X$ be a mapping having the mixed monotone property on $X$. Assume that there exist two elements $x_{0}, y_{0} \in X$ with

$$
x_{0} \preceq F\left(x_{0}, y_{0}\right) \text { and } y_{0} \succeq F\left(y_{0}, x_{0}\right) .
$$

Suppose there exist $\phi \in \Phi$ and $\psi \in \Psi$ such that

$$
\phi(p(F(x, y), F(u, v))) \leq \frac{1}{2} \phi(p(x, u)+p(y, v))-\psi\left(\frac{p(x, u)+p(y, v)}{2}\right)
$$

for all $x, y, u, v \in X$ with $x \succeq u$ and $y \preceq v$. Suppose either

(a) $F$ is continuous or

(b) $X$ has the following property:

(i) if a non-decreasing sequence $\left\{x_{n}\right\} \rightarrow x$, then $x_{n} \preceq x$, for all $n$,

(ii) if a non-increasing sequence $\left\{y_{n}\right\} \rightarrow y$, then $y \preceq y_{n}$, for all $n$. 
Then there exist $x, y \in X$ such that

$$
x=F(x, y) \text { and } y=F(y, x) \text {, }
$$

that is, $F$ has a coupled fixed point in $X$.

Proof Let $x_{0}, y_{0} \in X$ be such that $x_{0} \preceq F\left(x_{0}, y_{0}\right)$ and $y_{0} \succeq F\left(y_{0}, x_{0}\right)$. We construct sequences $\left\{x_{n}\right\}$ and $\left\{y_{n}\right\}$ in $X$ as

$$
x_{n+1}=F\left(x_{n}, y_{n}\right) \quad \text { and } \quad y_{n+1}=F\left(y_{n}, x_{n}\right) \quad \text { for all } n \geq 0 \text {. }
$$

We are to prove that

$$
x_{n} \preceq x_{n+1} \quad \text { for all } n \geq 0
$$

and

$$
y_{n} \succeq y_{n+1} \text { for all } n \geq 0 .
$$

For this we shall use mathematical induction.

Let $n=0$. Since $x_{0} \preceq F\left(x_{0}, y_{0}\right)$ and $y_{0} \succeq F\left(y_{0}, x_{0}\right)$ and as $x_{1}=F\left(x_{0}, y_{0}\right)$ and $y_{1}=F\left(y_{0}, x_{0}\right)$, we have $x_{0} \preceq x_{1}$ and $y_{0} \succeq y_{1}$. Thus (5) and (6) hold for $n=0$.

Suppose now that (5) and (6) hold for some fixed $n \geq 0$, then, since $x_{n} \preceq x_{n+1}$ and $y_{n} \succeq$ $y_{n+1}$, we have

$$
x_{n+2}=F\left(x_{n+1}, y_{n+1}\right) \succeq F\left(x_{n}, y_{n+1}\right) \succeq F\left(x_{n}, y_{n}\right)=x_{n+1}
$$

and

$$
y_{n+2}=F\left(y_{n+1}, x_{n+1}\right) \preceq F\left(y_{n}, x_{n+1}\right) \preceq F\left(y_{n}, x_{n}\right)=y_{n+1} .
$$

Using (7) and (8), we get

$$
x_{n+1} \preceq x_{n+2} \text { and } y_{n+1} \succeq y_{n+2} \text {. }
$$

Hence, by the induction method we conclude that (5) and (6) hold for all $n \geq 0$. Therefore,

$$
x_{0} \preceq x_{1} \preceq x_{2} \preceq \cdots \preceq x_{n} \preceq x_{n+1} \preceq \cdots
$$

and

$$
y_{0} \succeq y_{1} \succeq y_{2} \succeq \cdots \succeq y_{n} \succeq y_{n+1} \succeq \cdots
$$

Since $x_{n} \succeq x_{n-1}$ and $y_{n} \preceq y_{n-1}$, using (3) and (4), we have

$$
\begin{aligned}
\phi\left(p\left(x_{n+1}, x_{n}\right)\right) & =\phi\left(p\left(F\left(x_{n}, y_{n}\right), F\left(x_{n-1}, y_{n-1}\right)\right)\right) \\
& \leq \frac{1}{2} \phi\left(p\left(x_{n}, x_{n-1}\right)+p\left(y_{n}, y_{n-1}\right)\right)-\psi\left(\frac{p\left(x_{n}, x_{n-1}\right)+p\left(y_{n}, y_{n-1}\right)}{2}\right) .
\end{aligned}
$$


Similarly, since $y_{n-1} \succeq y_{n}$ and $x_{n-1} \preceq x_{n}$, using (3) and (4), we also have

$$
\begin{aligned}
\phi\left(p\left(y_{n}, y_{n+1}\right)\right) & =\phi\left(p\left(F\left(y_{n-1}, x_{n-1}\right), F\left(y_{n}, x_{n}\right)\right)\right) \\
& \leq \frac{1}{2} \phi\left(p\left(y_{n-1}, y_{n}\right)+p\left(x_{n-1}, x_{n}\right)\right)-\psi\left(\frac{p\left(y_{n-1}, y_{n}\right)+p\left(x_{n-1}, x_{n}\right)}{2}\right) .
\end{aligned}
$$

Using (11) and (12), we have

$$
\begin{aligned}
\phi\left(p\left(x_{n+1}, x_{n}\right)\right)+\phi\left(p\left(y_{n+1}, y_{n}\right)\right) \leq & \phi\left(p\left(x_{n}, x_{n-1}\right)+p\left(y_{n}, y_{n-1}\right)\right) \\
& -2 \psi\left(\frac{p\left(x_{n}, x_{n-1}\right)+p\left(y_{n}, y_{n-1}\right)}{2}\right) .
\end{aligned}
$$

By property $(\phi 3)$, we have

$$
\phi\left(p\left(x_{n+1}, x_{n}\right)+p\left(y_{n+1}, y_{n}\right)\right) \leq \phi\left(p\left(x_{n+1}, x_{n}\right)\right)+\phi\left(p\left(y_{n+1}, y_{n}\right)\right) .
$$

Using (13) and (14), we have

$$
\begin{aligned}
\phi\left(p\left(x_{n+1}, x_{n}\right)+p\left(y_{n+1}, y_{n}\right)\right) \leq & \phi\left(p\left(x_{n}, x_{n-1}\right)+p\left(y_{n}, y_{n-1}\right)\right) \\
& -2 \psi\left(\frac{p\left(x_{n}, x_{n-1}\right)+p\left(y_{n}, y_{n-1}\right)}{2}\right)
\end{aligned}
$$

which implies, since $\psi$ is a non-negative function,

$$
\phi\left(p\left(x_{n+1}, x_{n}\right)+p\left(y_{n+1}, y_{n}\right)\right) \leq \phi\left(p\left(x_{n}, x_{n-1}\right)+p\left(y_{n}, y_{n-1}\right)\right)
$$

Using the fact that $\phi$ is non-decreasing, we get

$$
p\left(x_{n+1}, x_{n}\right)+p\left(y_{n+1}, y_{n}\right) \leq p\left(x_{n}, x_{n-1}\right)+p\left(y_{n}, y_{n-1}\right) .
$$

Set

$$
\delta_{n}=p\left(x_{n+1}, x_{n}\right)+p\left(y_{n+1}, y_{n}\right) .
$$

Now, we show that $\delta_{n} \rightarrow 0$ as $n \rightarrow \infty$. It is clear that the sequence $\left\{\delta_{n}\right\}$ is decreasing. Therefore, there is some $\delta \geq 0$ such that

$$
\lim _{n \rightarrow \infty} \delta_{n}=\lim _{n \rightarrow \infty}\left[p\left(x_{n+1}, x_{n}\right)+p\left(y_{n+1}, y_{n}\right)\right]=\delta
$$

We shall prove that $\delta=0$. Suppose, to the contrary, that $\delta>0$. Then taking the limit as $n \rightarrow \infty$ (equivalently, $\delta_{n} \rightarrow \delta$ ) of both sides of (15) and remembering $\lim _{t \rightarrow r} \psi(t)>0$ for all $r>0$ and $\phi$ is continuous, we have

$$
\begin{aligned}
\phi(\delta) & =\lim _{n \rightarrow \infty} \phi\left(\delta_{n}\right) \leq \lim _{n \rightarrow \infty}\left[\phi\left(\delta_{n-1}\right)-2 \psi\left(\frac{\delta_{n-1}}{2}\right)\right] \\
& =\phi(\delta)-2 \lim _{\delta_{n-1} \rightarrow \delta} \psi\left(\frac{\delta_{n-1}}{2}\right)<\phi(\delta),
\end{aligned}
$$


a contradiction. Thus $\delta=0$, that is,

$$
\lim _{n \rightarrow \infty} \delta_{n}=\lim _{n \rightarrow \infty}\left[p\left(x_{n+1}, x_{n}\right)+p\left(y_{n+1}, y_{n}\right)\right]=0 .
$$

Let

$$
\delta_{n}^{s}=p^{s}\left(x_{n}, x_{n+1}\right)+p^{s}\left(y_{n}, y_{n+1}\right)
$$

for all $n \in \mathbb{N}$. From the definition of $p^{s}$, it is clear that $\delta_{n}^{s} \leq 2 \delta_{n}$ for all $n \in \mathbb{N}$. Using (17), we get

$$
\lim _{n \rightarrow+\infty} \delta_{n}^{s}=\lim _{n \rightarrow+\infty} p^{s}\left(x_{n}, x_{n+1}\right)+p^{s}\left(y_{n}, y_{n+1}\right)=0 .
$$

Now, we prove that $\left\{x_{n}\right\}$ and $\left\{y_{n}\right\}$ are Cauchy sequences in the partial metric space $(X, p)$. From Lemma 2.1, it is sufficient to prove that $\left\{x_{n}\right\}$ and $\left\{y_{n}\right\}$ are Cauchy sequences in the metric space $\left(X, p^{s}\right)$. Suppose, to the contrary, that at least one of $\left\{x_{n}\right\}$ or $\left\{y_{n}\right\}$ is not a Cauchy sequence. Then there exists an $\epsilon>0$ for which we can find subsequences $\left\{x_{n(k)}\right\}$, $\left\{x_{m(k)}\right\}$ of $\left\{x_{n}\right\}$ and $\left\{y_{n(k)}\right\},\left\{y_{m(k)}\right\}$ of $\left\{y_{n}\right\}$ with $n(k)>m(k) \geq k$ such that

$$
p^{s}\left(x_{n(k)}, x_{m(k)}\right)+p^{s}\left(y_{n(k)}, y_{m(k)}\right) \geq \epsilon .
$$

Further, corresponding to $m(k)$, we can choose $n(k)$ in such a way that it is the smallest integer with $n(k)>m(k)$ and satisfying (18). Then

$$
p^{s}\left(x_{n(k)-1}, x_{m(k)}\right)+p^{s}\left(y_{n(k)-1}, y_{m(k)}\right)<\epsilon .
$$

Using (18), (19) and the triangle inequality, we have

$$
\begin{aligned}
\epsilon & \leq r_{k}^{s}:=p^{s}\left(x_{n(k)}, x_{m(k)}\right)+p^{s}\left(y_{n(k)}, y_{m(k)}\right) \\
& \leq p^{s}\left(x_{n(k)}, x_{n(k)-1}\right)+p^{s}\left(x_{n(k)-1}, x_{m(k)}\right)+p^{s}\left(y_{n(k)}, y_{n(k)-1}\right)+p^{s}\left(y_{n(k)-1}, y_{m(k)}\right) \\
& \leq p^{s}\left(x_{n(k)}, x_{n(k)-1}\right)+p^{s}\left(y_{n(k)}, y_{n(k)-1}\right)+\epsilon .
\end{aligned}
$$

Letting $k \rightarrow \infty$ and using (17), we get

$$
\lim _{k \rightarrow \infty} r_{k}^{s}=\lim _{k \rightarrow \infty}\left[p^{s}\left(x_{n(k)}, x_{m(k)}\right)+p^{s}\left(y_{n(k)}, y_{m(k)}\right)\right]=\epsilon .
$$

By the triangle inequality,

$$
\begin{aligned}
r_{k}^{s}= & p^{s}\left(x_{n(k)}, x_{m(k)}\right)+p^{s}\left(y_{n(k)}, y_{m(k)}\right) \\
\leq & p^{s}\left(x_{n(k)}, x_{n(k)+1}\right)+p^{s}\left(x_{n(k)+1}, x_{m(k)+1}\right)+p^{s}\left(x_{m(k)+1}, x_{m(k)}\right) \\
& +p^{s}\left(y_{n(k)}, y_{n(k)+1}\right)+p^{s}\left(y_{n(k)+1}, y_{m(k)+1}\right)+p^{s}\left(y_{m(k)+1}, y_{m(k)}\right) \\
= & \delta_{n(k)}^{s}+\delta_{m(k)}^{s}+p^{s}\left(x_{n(k)+1}, x_{m(k)+1}\right)+p^{s}\left(y_{n(k)+1}, y_{m(k)+1}\right) .
\end{aligned}
$$


Using the properties of $\phi$, we have

$$
\begin{aligned}
\phi\left(r_{k}^{s}\right) & \leq \phi\left(\delta_{n(k)}^{s}+\delta_{m(k)}^{s}+p^{s}\left(x_{n(k)+1}, x_{m(k)+1}\right)+p^{s}\left(y_{n(k)+1}, y_{m(k)+1}\right)\right) \\
& \leq \phi\left(\delta_{n(k)}^{s}+\delta_{m(k)}^{s}\right)+\phi\left(p^{s}\left(x_{n(k)+1}, x_{m(k)+1}\right)\right)+\phi\left(p^{s}\left(y_{n(k)+1}, y_{m(k)+1}\right)\right) .
\end{aligned}
$$

Now, let

$$
r_{k}=p\left(x_{n(k)}, x_{m(k)}\right)+p\left(y_{n(k)}, y_{m(k)}\right) .
$$

By the definition of $r_{k}^{s}$, we have

$$
\begin{aligned}
r_{k}^{s}= & p^{s}\left(x_{n(k)}, x_{m(k)}\right)+p^{s}\left(y_{n(k)}, y_{m(k)}\right) \\
= & 2 p\left(x_{n(k)}, x_{m(k)}\right)-p\left(x_{n(k)}, x_{n(k)}\right)-p\left(x_{m(k)}, x_{m(k)}\right) \\
& +2 p\left(y_{n(k)}, y_{m(k)}\right)-p\left(y_{n(k)}, y_{n(k)}\right)-p\left(y_{m(k)}, y_{m(k)}\right) \\
= & 2 r_{k}-p\left(x_{n(k)}, x_{n(k)}\right)-p\left(x_{m(k)}, x_{m(k)}\right) \\
& -p\left(y_{n(k)}, y_{n(k)}\right)-p\left(y_{m(k)}, y_{m(k)}\right) .
\end{aligned}
$$

In view of property (p2) and (17), we have

$$
\begin{aligned}
\lim _{k \rightarrow+\infty} p\left(x_{n(k)}, x_{n(k)}\right) & =\lim _{k \rightarrow+\infty} p\left(x_{m(k)}, x_{m(k)}\right) \\
& =\lim _{k \rightarrow+\infty} p\left(y_{n(k)}, y_{n(k)}\right) \\
& =\lim _{k \rightarrow+\infty} p\left(y_{m(k)}, y_{m(k)}\right)=0 .
\end{aligned}
$$

Therefore, letting $k \rightarrow+\infty$ in (22) and using (20), we get

$$
\lim _{k \rightarrow+\infty} r_{k}=\frac{\epsilon}{2}
$$

Since $x_{n(k)} \succeq x_{m(k)}$ and $y_{n(k)} \preceq y_{m(k)}$, we have

$$
\begin{aligned}
\phi\left(p^{s}\left(x_{n(k)+1}, x_{m(k)+1}\right)\right) \leq & \phi\left(2 p\left(x_{n(k)+1}, x_{m(k)+1}\right)\right) \\
\leq & 2 \phi\left(p\left(x_{n(k)+1}, x_{m(k)+1}\right)\right) \\
= & 2 \phi\left(p\left(F\left(x_{n(k)}, y_{n(k)}\right)\right), p\left(F\left(x_{m(k)}, y_{m(k)}\right)\right)\right) \\
\leq & \phi\left(p\left(x_{n(k)}, x_{m(k)}\right)+p\left(y_{n(k)}, y_{m(k)}\right)\right) \\
& -2 \psi\left(\frac{p\left(x_{n(k)}, x_{m(k)}\right)+p\left(y_{n(k)}, y_{m(k)}\right)}{2}\right) \\
= & \phi\left(r_{k}\right)-2 \psi\left(\frac{r_{k}}{2}\right) .
\end{aligned}
$$

Similarly,

$$
\begin{aligned}
\phi\left(p^{s}\left(y_{n(k)+1}, y_{m(k)+1}\right)\right) & \leq \phi\left(2 p\left(y_{n(k)+1}, y_{m(k)+1}\right)\right) \\
& \leq 2 \phi\left(p\left(y_{n(k)+1}, y_{m(k)+1}\right)\right)
\end{aligned}
$$




$$
\begin{aligned}
= & 2 \phi\left(p\left(F\left(y_{n(k)}, x_{n(k)}\right)\right), p\left(F\left(y_{m(k)}, x_{m(k)}\right)\right)\right) \\
\leq & \phi\left(p\left(y_{n(k)}, y_{m(k)}\right)+p\left(x_{n(k)}, x_{m(k)}\right)\right) \\
& -2 \psi\left(\frac{p\left(y_{n(k)}, y_{m(k)}\right)+p\left(x_{n(k)}, x_{m(k)}\right)}{2}\right) \\
= & \phi\left(r_{k}\right)-2 \psi\left(\frac{r_{k}}{2}\right) .
\end{aligned}
$$

Adding (23) and (24), we get

$$
\phi\left(p^{s}\left(x_{n(k)+1}, x_{m(k)+1}\right)\right)+\phi\left(p^{s}\left(y_{n(k)+1}, y_{m(k)+1}\right)\right) \leq 2 \phi\left(r_{k}\right)-4 \psi\left(\frac{r_{k}}{2}\right)
$$

Thus, from (21), we have

$$
\phi\left(r_{k}^{s}\right) \leq \phi\left(\delta_{n(k)}^{s}+\delta_{m(k)}^{s}\right)+2 \phi\left(r_{k}\right)-4 \psi\left(\frac{r_{k}}{2}\right)
$$

Letting $k \rightarrow+\infty$, and using the properties of $\phi$ and $\psi$ together with the inequalities established above, we have

$$
\begin{aligned}
\phi(\epsilon) & \leq \phi(0)+2 \phi\left(\frac{\epsilon}{2}\right)-4 \lim _{k \rightarrow+\infty} \psi\left(\frac{r_{k}}{2}\right) \leq \phi(\epsilon)-4 \lim _{\frac{r_{k}}{2} \rightarrow \frac{\epsilon}{4}} \psi\left(\frac{r_{k}}{2}\right) \\
& \leq \phi(\epsilon)-4 \lim _{t \rightarrow \frac{\epsilon}{4}} \psi(t)<\phi(\epsilon),
\end{aligned}
$$

which is a contradiction. Therefore, $\left\{x_{n}\right\}$ and $\left\{y_{n}\right\}$ are Cauchy sequences in the complete metric space $\left(X, p^{s}\right)$. Thus, there are $x, y \in X$ such that

$$
\lim _{n \rightarrow+\infty} p^{s}\left(x_{n}, x\right)=\lim _{n \rightarrow+\infty} p^{s}\left(y_{n}, y\right)=0,
$$

which implies that

$$
\begin{aligned}
& \lim _{n \rightarrow+\infty} F\left(x_{n}, y_{n}\right)=\lim _{n \rightarrow+\infty} x_{n}=x, \\
& \lim _{n \rightarrow+\infty} F\left(y_{n}, x_{n}\right)=\lim _{n \rightarrow+\infty} y_{n}=y .
\end{aligned}
$$

Therefore, from Lemma 2.1, using (17) and the property (p2), we have

$$
\begin{aligned}
& p(x, x)=\lim _{n \rightarrow+\infty} p\left(x_{n}, x\right)=\lim _{n \rightarrow+\infty} p\left(x_{n}, x_{n}\right)=0, \\
& p(y, y)=\lim _{n \rightarrow+\infty} p\left(y_{n}, y\right)=\lim _{n \rightarrow+\infty} p\left(y_{n}, y_{n}\right)=0 .
\end{aligned}
$$

We now show that $x=F(x, y)$ and $y=F(y, x)$. Suppose that the assumption (a) holds.

As $F$ is continuous at $(x, y)$, so for any $\epsilon>0$, there exists $\delta>0$ such that if $(u, v) \in X \times X$ with $v((x, y),(u, v))<v((x, y),(x, y))+\delta=\delta$, meaning that

$$
p(x, u)+p(y, v)<p(x, x)+p(y, y)+\delta=\delta
$$


because $p(x, x)=p(y, y)=0$. Then we have

$$
p(F(x, y), F(u, v))<p(F(x, y), F(x, y))+\frac{\epsilon}{2} .
$$

Since $\lim _{n \rightarrow+\infty} p\left(x_{n}, x\right)=\lim _{n \rightarrow+\infty} p\left(y_{n}, y\right)=0$, for $\eta=\min \left(\frac{\delta}{2}, \frac{\epsilon}{2}\right)>0$, there exist $n_{0}, m_{0} \in$ $\mathbb{N}$ such that, for $n \geq n_{0}, m \geq m_{0}$,

$$
p\left(x_{n}, x\right)<\eta \quad \text { and } \quad p\left(y_{m}, y\right)<\eta \text {. }
$$

Then for $n \in \mathbb{N}, n \geq \max \left(n_{0}, m_{0}\right)$, we have $p\left(x_{n}, x\right)+p\left(y_{n}, y\right)<2 \eta<\delta$, so we get

$$
p\left(F(x, y), F\left(x_{n}, y_{n}\right)\right)<p(F(x, y), F(x, y))+\frac{\epsilon}{2} .
$$

Further, for any $n \geq \max \left(n_{0}, m_{0}\right)$, by using (30), we have

$$
\begin{aligned}
p(F(x, y), x) & \leq p\left(F(x, y), x_{n+1}\right)+p\left(x_{n+1}, x\right) \\
& =p\left(F(x, y), F\left(x_{n}, y_{n}\right)\right)+p\left(x_{n+1}, x\right) \\
& \leq p(F(x, y), F(x, y))+\frac{\epsilon}{2}+\eta \\
& \leq p(F(x, y), F(x, y))+\epsilon .
\end{aligned}
$$

On utilizing $p(x, x)=p(y, y)=0$ in (3), we get

$$
\begin{aligned}
\phi(p(F(x, y), F(x, y))) & \leq \frac{1}{2} \phi(p(x, x)+p(y, y))-\psi\left(\frac{p(x, x)+p(y, y)}{2}\right) \\
& =\frac{1}{2} \phi(0)-\psi(0)=-\psi(0) \leq 0
\end{aligned}
$$

which implies $p(F(x, y), F(x, y))=0$. Hence, for any $\epsilon>0$, (31) implies that

$$
p(F(x, y), x)<\epsilon
$$

Thus, we have $F(x, y)=x$. Similarly, we can show that $F(y, x)=y$.

Finally, suppose that (b) holds. By (5), (26) and (27), we have $\left\{x_{n}\right\}$ is a non-decreasing sequence, $x_{n} \rightarrow x$ and $\left\{y_{n}\right\}$ is a non-increasing sequence, $y_{n} \rightarrow y$ as $n \rightarrow \infty$. Hence, by the assumption (b), we have for all $n \geq 0$,

$$
x_{n} \preceq x \text { and } y_{n} \succeq y \text {. }
$$

By property (p4), we have

$$
p(x, F(x, y)) \leq p\left(x, x_{n+1}\right)+p\left(x_{n+1}, F(x, y)\right)=p\left(x, x_{n+1}\right)+p\left(F\left(x_{n}, y_{n}\right), F(x, y)\right) .
$$

Therefore,

$$
\begin{aligned}
\phi(p(x, F(x, y))) & \leq \phi\left(p\left(x, x_{n+1}\right)\right)+\phi\left(p\left(F\left(x_{n}, y_{n}\right), F(x, y)\right)\right) \\
& \leq \phi\left(p\left(x, x_{n+1}\right)\right)+\frac{1}{2} \phi\left(p\left(x_{n}, x\right)+p\left(y_{n}, y\right)\right)-\psi\left(\frac{p\left(x_{n}, x\right)+p\left(y_{n}, y\right)}{2}\right) .
\end{aligned}
$$


Taking limit as $n \rightarrow \infty$ in the above inequality, using (31) and (29) and the properties of $\phi$ and $\psi$, we get $\phi(p(x, F(x, y)))=0$, which implies $p(x, F(x, y))=0$. Hence, $x=F(x, y)$. Similarly, we can show that $y=F(y, x)$. Thus $F$ has a coupled fixed point.

Remark 3.1 Note that the property $(\phi 4)$ is utilized only to get the inequality (25). Thus the conclusion of Theorem 3.1 holds if we drop property $(\phi 4)$ and assume the additivity in $(\phi 3)$, i.e., $\phi(t+s)=\phi(t)+\phi(s), \forall t, s \in[0, \infty)$.

As an immediate consequence of the above theorem, by taking $\phi(t)=t$, we have:

Corollary 3.1 Let $(X, \preceq)$ be a partially ordered set and suppose there is a partial metric $p$ on $X$ such that $(X, d)$ is a complete partial metric space. Let $F: X \times X \rightarrow X$ be a mapping having the mixed monotone property on $X$. Assume that there exist two elements $x_{0}, y_{0} \in X$ with

$$
x_{0} \preceq F\left(x_{0}, y_{0}\right) \quad \text { and } \quad y_{0} \succeq F\left(y_{0}, x_{0}\right) .
$$

Suppose there exist $\phi \in \Phi$ and $\psi \in \Psi$ such that

$$
p(F(x, y), F(u, v)) \leq \frac{1}{2}(p(x, u)+p(y, v))-\psi\left(\frac{p(x, u)+p(y, v)}{2}\right)
$$

for all $x, y, u, v \in X$ with $x \succeq u$ and $y \preceq v$. Suppose either

(a) $F$ is continuous or

(b) $X$ has the following property:

(i) if a non-decreasing sequence $\left\{x_{n}\right\} \rightarrow x$, then $x_{n} \preceq x$ for all $n$,

(ii) if a non-increasing sequence $\left\{y_{n}\right\} \rightarrow y$, then $y \preceq y_{n}$ for all $n$.

Then there exist $x, y \in X$ such that

$$
x=F(x, y) \quad \text { and } \quad y=F(y, x) \text {, }
$$

that is, $F$ has a coupled fixed point in $X$.

Moreover, if we take $\psi(t)=\frac{1-k}{2} t$ where $k \in[0,1)$ in Corollary 3.1, we get:

Corollary 3.2 Let $(X, \preceq)$ be a partially ordered set and suppose there is a partial metric $p$ on $X$ such that $(X, d)$ is a complete partial metric space. Let $F: X \times X \rightarrow X$ be a mapping having the mixed monotone property on $X$. Assume that there exist two elements $x_{0}, y_{0} \in X$ with

$$
x_{0} \preceq F\left(x_{0}, y_{0}\right) \text { and } y_{0} \succeq F\left(y_{0}, x_{0}\right) .
$$

Suppose there exist $\phi \in \Phi$ and $\psi \in \Psi$ such that

$$
p(F(x, y), F(u, v)) \leq \frac{k}{2}(p(x, u)+p(y, v))
$$

for all $x, y, u, v \in X$ with $x \succeq u$ and $y \preceq v$. Suppose either 
(a) $F$ is continuous or

(b) $X$ has the following property:

(i) if a non-decreasing sequence $\left\{x_{n}\right\} \rightarrow x$, then $x_{n} \preceq x$ for all $n$,

(ii) if a non-increasing sequence $\left\{y_{n}\right\} \rightarrow y$, then $y \preceq y_{n}$ for all $n$.

Then there exist $x, y \in X$ such that

$$
x=F(x, y) \quad \text { and } \quad y=F(y, x) \text {, }
$$

that is, F has a coupled fixed point in $X$.

Recently, Alotaibi and Alsulami [10] extended Luong and Thuan's [9] main result to coupled coincidences using the notion of compatible maps. Here we extend these results to partial metric spaces without the condition of compatible maps. We shall need the following lemma.

Lemma 3.1 (see [16-18]) Let $X$ be a nonempty set and $g: X \rightarrow X$ be a mapping. Then there exists a subset $E \subseteq X$ such that $g(E)=g(X)$ and $g: E \rightarrow X$ is one-to-one.

Theorem 3.2 Let $(X, \preceq)$ be a partially ordered set and suppose there is a partial metric $p$ on $X$ such that $(X, d)$ is a partial metric space. Let $g: X \rightarrow X$ and $F: X \times X \rightarrow X$ be a mapping having the mixed $g$-monotone property on $X$ such that there exist two elements $x_{0}, y_{0} \in X$ with

$$
g x_{0} \preceq F\left(x_{0}, y_{0}\right) \quad \text { and } \quad g y_{0} \succeq F\left(y_{0}, x_{0}\right) \text {. }
$$

Suppose there exist $\phi \in \Phi$ and $\psi \in \Psi$ such that

$$
\phi(p(F(x, y), F(u, v))) \leq \frac{1}{2} \phi(p(g x, g u)+p(g y, g v))-\psi\left(\frac{p(g x, g u)+p(g y, g v)}{2}\right)
$$

for all $x, y, u, v \in X$ with $g x \succeq g u$ and $g y \preceq g v$. Suppose $F(X \times X) \subseteq g(X), g$ is continuous and $g(X)$ is complete and also suppose either

(a) $F$ is continuous or

(b) $X$ has the following property:

(i) if a non-decreasing sequence $\left\{x_{n}\right\} \rightarrow x$, then $x_{n} \preceq x$ for all $n$,

(ii) if a non-increasing sequence $\left\{y_{n}\right\} \rightarrow y$, then $y \preceq y_{n}$ for all $n$.

Then there exist $x, y \in X$ such that

$$
g x=F(x, y) \text { and } g y=F(y, x) \text {, }
$$

that is, $F$ and $g$ have a coupled coincidence point in $X$.

Proof Using Lemma 3.1, there exists $E \subseteq X$ such that $g(E)=g(X)$ and $g: E \rightarrow X$ is one-toone. We define a mapping $G: g(E) \times g(E) \rightarrow X$ by

$$
G(g x, g y)=F(x, y),
$$


for all $g x, g y \in g(E)$. As $g$ is one-to-one on $g(E)$, so $G$ is well defined. Thus, it follows from (33) and (34) that

$$
\begin{aligned}
& \phi(p(G(g x, g y), G(g u, g v))) \\
& \quad=\phi(p(F(x, y), F(u, v))) \\
& \quad \leq \frac{1}{2} \phi(p(g x, g u)+p(g y, g v))-\psi\left(\frac{p(g x, g u)+p(g y, g v)}{2}\right)
\end{aligned}
$$

for all $g x, g y, g u, g v \in g(X)$ for which $g(x) \preceq g(u)$ and $g(y) \succeq g(v)$. Since $F$ has the mixed $g$-monotone property, for all $g x, g y \in g(X)$,

$$
g x_{1}, g x_{2} \in g(X), \quad g\left(x_{1}\right) \preceq g\left(x_{2}\right) \quad \text { implies } G\left(g x_{1}, g y\right) \preceq G\left(g x_{2}, g y\right)
$$

and

$$
g y_{1}, g y_{2} \in g(X), \quad g\left(y_{1}\right) \preceq g\left(y_{2}\right) \quad \text { implies } G\left(g x, g y_{1}\right) \succeq G\left(g x, g y_{2}\right),
$$

which implies that $G$ has the mixed monotone property. Also, there exist $x_{0}, y_{0} \in X$ such that

$$
g\left(x_{0}\right) \preceq F\left(x_{0}, y_{0}\right) \quad \text { and } \quad g\left(y_{0}\right) \succeq F\left(y_{0}, x_{0}\right) \text {. }
$$

This implies there exist $g x_{0}, g y_{0} \in g(X)$ such that

$$
g\left(x_{0}\right) \preceq G\left(g x_{0}, g y_{0}\right) \quad \text { and } \quad g\left(y_{0}\right) \succeq G\left(g y_{0}, g x_{0}\right) \text {. }
$$

Suppose that the assumption (a) holds. Since $F$ is continuous, $G$ is also continuous. Using Theorem 3.1 with the mapping $G$, it follows that $G$ has a coupled fixed point $(u, v) \in g(X) \times$ $g(X)$.

Suppose that the assumption (b) holds. We conclude similarly that the mapping $G$ has a coupled fixed point $(u, v) \in g(X) \times g(X)$. Finally, we prove that $F$ and $g$ have a coupled coincidence point. Since $(u, v)$ is a coupled fixed point of $G$, we get

$$
u=G(u, v) \text { and } \quad v=G(v, u) .
$$

Since $(u, v) \in g(X) \times g(X)$, there exists a point $\left(u_{0}, v_{0}\right) \in X \times X$ such that

$$
u=g u_{0} \quad \text { and } \quad v=g v_{0} .
$$

It follows from (38) and (39) that

$$
g u_{0}=G\left(g u_{0}, g v_{0}\right) \text { and } g v_{0}=G\left(g v_{0}, g u_{0}\right) \text {. }
$$

Combining (34) and (40), we get

$$
g u_{0}=F\left(u_{0}, v_{0}\right) \text { and } g v_{0}=F\left(v_{0}, u_{0}\right) \text {. }
$$


Thus, $\left(u_{0}, v_{0}\right)$ is a required coupled coincidence point of $F$ and $g$. This completes the proof.

The following coupled coincidence point theorems are obtained respectively from Corollaries 3.1 and 3.2 in a similar way as Theorem 3.2 from Theorem 3.1.

Theorem 3.3 Let $(X, \preceq)$ be a partially ordered set, and suppose there is a partial metric $p$ on $X$ such that $(X, p)$ is a partial metric space. Let $g: X \rightarrow X$ and $F: X \times X \rightarrow X$ be a mapping having the mixed $g$-monotone property on $X$ such that there exist two elements $x_{0}, y_{0} \in X$ with

$$
g x_{0} \preceq F\left(x_{0}, y_{0}\right) \quad \text { and } \quad g y_{0} \succeq F\left(y_{0}, x_{0}\right) \text {. }
$$

Suppose there exist $\phi \in \Phi$ and $\psi \in \Psi$ such that

$$
\phi(p(F(x, y), F(u, v))) \leq \frac{1}{2}(p(g x, g u)+p(g y, g v))-\psi\left(\frac{p(g x, g u)+p(g y, g v)}{2}\right)
$$

for all $x, y, u, v \in X$ with $g x \succeq g u$ and $g y \preceq g \nu$. Suppose $F(X \times X) \subseteq g(X), g$ is continuous and $g(X)$ is complete and also suppose either

(a) $F$ is continuous or

(b) $X$ has the following property:

(i) if a non-decreasing sequence $\left\{x_{n}\right\} \rightarrow x$, then $x_{n} \preceq x$ for all $n$,

(ii) if a non-increasing sequence $\left\{y_{n}\right\} \rightarrow y$, then $y \preceq y_{n}$ for all $n$.

Then there exist $x, y \in X$ such that

$$
g x=F(x, y) \text { and } g y=F(y, x) \text {, }
$$

that is, $F$ and $g$ have a coupled coincidence point in $X$.

Theorem 3.4 Let $(X, \preceq)$ be a partially ordered set and suppose there is a partial metric $p$ on $X$ such that $(X, d)$ is a complete partial metric space. Let $g: X \rightarrow X$ and $F: X \times X \rightarrow X$ be a mapping having the mixed $g$-monotone property on $X$ such that there exist two elements $x_{0}, y_{0} \in X$ with

$$
g x_{0} \preceq F\left(x_{0}, y_{0}\right) \quad \text { and } \quad g y_{0} \succeq F\left(y_{0}, x_{0}\right) .
$$

Suppose there exist $\phi \in \Phi$ and $\psi \in \Psi$ such that

$$
\phi(p(F(x, y), F(u, v))) \leq \frac{k}{2}(p(g x, g u)+p(g y, g v))
$$

for all $x, y, u, v \in X$ with $g x \succeq g u$ and $g y \preceq g \nu$. Suppose $F(X \times X) \subseteq g(X), g$ is continuous and $g(X)$ is complete and also suppose either

(a) $F$ is continuous or

(b) $X$ has the following property:

(i) if a non-decreasing sequence $\left\{x_{n}\right\} \rightarrow x$, then $x_{n} \preceq x$ for all $n$,

(ii) if a non-increasing sequence $\left\{y_{n}\right\} \rightarrow y$, then $y \preceq y_{n}$ for all $n$. 
Then there exist $x, y \in X$ such that

$$
g x=F(x, y) \text { and } g y=F(y, x) \text {, }
$$

that is, $F$ and g have a coupled coincidence point in $X$.

Remark 3.2 From the proof of Theorem 3.2 we conclude that Theorems 3.3, 4.4 and 5.4 in [6] hold without the compatibility of the maps $(F, g)$.

\section{Competing interests}

The authors declare that they have no competing interests.

\section{Authors' contributions}

All authors contributed equally and significantly in writing this article. All authors read and approved the final manuscript.

\section{Acknowledgements}

This paper was funded by the Deanship of Scientific Research (DSR), King Abdulaziz University, Jeddah, under Grant No. (113-130-D1432). The authors, therefore, acknowledge with thanks DSR technical and financial support.

Received: 26 August 2012 Accepted: 25 September 2012 Published: 9 October 2012

\section{References}

1. Khamsi, MA, Kirk, WA: An Introduction to Metric Spaces and Fixed Point Theory. Wiley, New York (2001)

2. Matthews, SG: Partial metric topology. Ann. N.Y. Acad. Sci. 728, 183-197 (1994). In: Proc. 8th Summer Conference on General Topology and Applications

3. Ćirić, L, Samet, B, Aydi, H, Vetro, C: Common fixed points of generalized contractions on partial metric spaces and an application. Appl. Math. Comput. 218, 2398-2406 (2011)

4. Shatanawi, W, Samet, B, Abbas, M: Coupled fixed point theorems for mixed monotone mappings in ordered partial metric spaces. Math. Comput. Model. 55, 680-687 (2012)

5. Ilić, D, Pavlović, V, Rakocević, V: Some new extensions of Banach's contraction principle to partial metric spaces. Appl. Math. Lett. 24, 1326-1330 (2011)

6. Gulubović, Z, Kadelburg, Z, Radenović, S: Coupled coincidence points of mappings in ordered partial metric spaces. Abstr. Appl. Anal. 2012, Article ID 192581 (2012)

7. Oltra, S, Valero, O: Banach's fixed point theorem for partial metric spaces. Rend. Ist. Mat. Univ. Trieste 36, 17-26 (2004)

8. Bhaskar, TG, Lakshmikantham, V: Fixed point theorems in partially ordered metric spaces and applications. Nonlinear Anal. 65, 1379-1393 (2006)

9. Luong, NV, Thuan, NX: Coupled fixed point in partially ordered metric spaces and applications. Nonlinear Anal. 74 983-992 (2011)

10. Alotaibi, A, Alsulami, S: Coupled coincidence points for monotone operators in partially ordered metric spaces. Fixed Point Theory Appl. 2011, 44 (2011)

11. Lakshmikantham, V, Ćirić, L: Coupled fixed point theorems for nonlinear contractions in partially ordered metric spaces. Nonlinear Anal. 70, 4341-4349 (2009)

12. Choudhury, BS, Kundu, A: A coupled coincidence point result in partially ordered metric spaces for compatible mappings. Nonlinear Anal. 73, 2524-2531 (2010)

13. Cho, YJ, Shah, MH, Hussain, N: Coupled fixed points of weakly F-contractive mappings in topological spaces. Appl. Math. Lett. 24, 1185-1190 (2011)

14. Hussain, N, Shah, MH, Kutbi, MA: Coupled coincidence point theorems for nonlinear contractions in partially ordered quasi-metric spaces with a Q-function. Fixed Point Theory Appl. 2011, Article ID 703938 (2011)

15. Hussain, N, Alotaibi, A: Coupled coincidences for multi-valued nonlinear contractions in partially ordered metric spaces. Fixed Point Theory Appl. 2011, 82 (2011)

16. Hussain, N, Latif, A, Shah, MH: Coupled and tripled coincidence point results without compatibility. Fixed Point Theory Appl. 2011, 77 (2012)

17. Sintunavarat, W, Cho, YJ, Kumam, P: Coupled coincidence point theorems for contractions without commutative condition in intuitionistic fuzzy normed spaces. Fixed Point Theory Appl. 2011, 81 (2011)

18. Hussain, N, Kadelburg, Z, Radenovic, S, Al-Solamy, FR: Comparison functions and fixed point results in partial metric spaces. Abstr. Appl. Anal. 2012, Article ID 605781 (2012)

doi:10.1186/1687-1812-2012-173

Cite this article as: Alsulami et al.: Coupled fixed and coincidence points for monotone operators in partial metric spaces. Fixed Point Theory and Applications 2012 2012:173. 